\title{
A questionnaire based study of students' opinion on the teaching and learning methods in pharmacology in a medical school of India
}

\author{
Prasad SR*, Ravi H. Kudthni, Santhosh R.
}

Department of Pharmacology, Shridevi Institute of Medical Sciences and Research Hospital, Tumkur, Karnataka, India

Received: 15 September 2016 Accepted: 20 October 2016

*Correspondence to:

Dr. Prasad SR,

Email: prasadrudresh@ gmail.com

Copyright: (C) the author(s), publisher and licensee Medip Academy. This is an openaccess article distributed under the terms of the Creative Commons Attribution NonCommercial License, which permits unrestricted noncommercial use, distribution, and reproduction in any medium, provided the original work is properly cited.

\begin{abstract}
Background: Pharmacology as a discipline is undergoing continuous development. It is generally agreed that reviewing the teaching program at regular intervals and modifications in the methodologies of imparting basic knowledge about drugs and drug therapies is a must. Students' perceptions and attitude regarding the different teaching-learning and evaluation methods are important for further development and restructuring of medical education in future. The present study was undertaken to gather students' perception about pharmacology teaching and learning methods.

Methods: A 20 item prevalidated Questionnaire proforma was distributed to two batches of undergraduate medical students. The completed questionnaires were collected and data was analysed.

Results: Of the 100 students who answered, 62\% students considered the importance of pharmacology above all subjects. Among the various topics central nervous system $60 \%$, chemotherapy $52 \%$ and cardiovascular pharmacology $42 \%$ were considered the most interesting topics. Of the teaching methodologies, more than half of the students $(62 \%)$ found interactive lectures most helpful, whilst $39 \%$ rated audio-visual aided lectures. In terms of reforms, $48 \%$ of the students suggested to introduce small group discussion hours, $44 \%$ suggested making use of more audio-visual aids and $21 \%$ wanted more clinical pharmacology. Discussions at the end of class (55\%), encouraging students to ask questions during lectures (38\%) were main ways to enhance active student participation.

Conclusions: The results of our study revealed a positive feedback from students which will help in making the teaching programme in pharmacology more interesting and relevant.
\end{abstract}

Keywords: Medical students, Pharmacology, Perception, Teaching learning

\section{INTRODUCTION}

Pharmacology as a discipline is undergoing continuous development and is becoming an important component of all areas of medicine. Prescribing skills of newly graduated doctors largely depend upon good foundation in pharmacology. To acquire the necessary prescribing skills it is important that medical students appreciate pharmacological principles and understand their application in clinical situations. ${ }^{1}$

Consequently, reforms in undergraduate teaching are the need of the hour. It is generally agreed that reviewing the teaching program at regular intervals and modifications in the methodologies of imparting basic knowledge about drugs and drug therapies is a must. Many attempts have been made by various colleges all over India and abroad to make the teaching of pharmacology more interesting and relevant. ${ }^{2}$

Traditionally, the teaching of pharmacology in medical schools follows a discipline-based and lecture-based approach with a heavy emphasis on acquiring factual knowledge concerning drugs. Also pharmacy, animal experiments, prescription writing, and clinical problems solving included additionally. It is difficult to mend student perception with traditional methods of teaching, though some modification in teaching-learning 
methodology could be tried. Such attempts have been made all over India to make the teaching of pharmacology more interesting and relevant. ${ }^{3,4}$

In recent years undergraduate training in pharmacology has been revolutionized with adoptions of new methods of teaching that focus on supportive learning through novel teaching approaches like small group discussions, role plays, computer assisted learning, using audio-visual aids, clinical and community pharmacology studies. ${ }^{5,6}$

Students' feedback would probably reveal whether the so-called reforms are acceptable to them and their opinion for the betterment of teaching/learning Pharmacology subject. Hence, the present study was undertaken to gather undergraduate medical students' perception about pharmacology as a subject, its usefulness in future practice, the teaching methods currently in use and their patterns of learning and preparing for examinations at the department of pharmacology, Shridevi Institute of Medical Sciences and Research Hospital, Tumkur, Karnataka, India.

\section{METHODS}

This was a cross-sectional study based on the questionnaire. Study was planned and executed by the department of Pharmacology, Shridevi Institute of Medical Sciences and Research Hospital, Tumkur among undergraduate medical students. Study Population included V term and VI term undergraduate medical students studying in Shridevi Institute of Medical Sciences and Research Hospital. Prior permission was obtained from the Institutional Ethics Committee before the commencement of the study. Informed consent was obtained from the study participants.

A 20 item self-administered prevalidated Questionnaire proforma was distributed to the students in the classrooms just after completion of classes by the investigators following a brief explanation of the objectives and data processing procedures, including anonymity and the importance of voluntary based participation. The questionnaire was designed based on the literature review in this field and suitably modified to suit to our teaching curriculum. ${ }^{7,8}$ It had multiple options and students were free to opt for more than one options.

The main categories explored in the questionnaire were in reference to students' perception of pharmacology as a subject, teaching methodologies employed and the resources they utilized to learn pharmacology. The time allocated for the completion of the questionnaire was 30 minutes. It was also explained that the data would be used for quality assurance, as well as, for research purpose with a request for their co-operation. The completed questionnaire was collected and data was analyzed. The results were expressed as percentage responses.

\section{RESULTS}

Of the 117 students, 100 completed the study. Among these 100 students who answered, $49 \%$ knew somewhat about pharmacology, $16 \%$ knew about it but $35 \%$ did not know the subject at all before being introduced in the second year.

While $62 \%$ students considered the importance of pharmacology above all subjects, $35 \%$ considered pharmacology at par with other subjects, $3 \%$ regarded it as one of the few most important subjects.

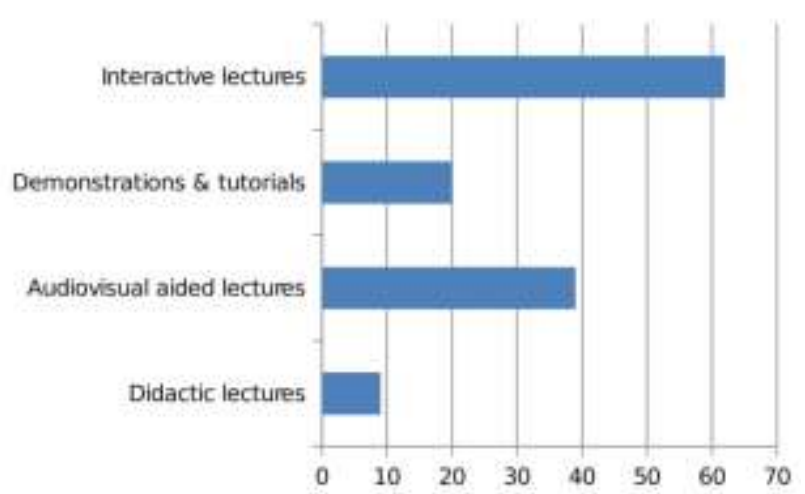

Figure 1: Students preference on teaching methodologies $(\%)$.

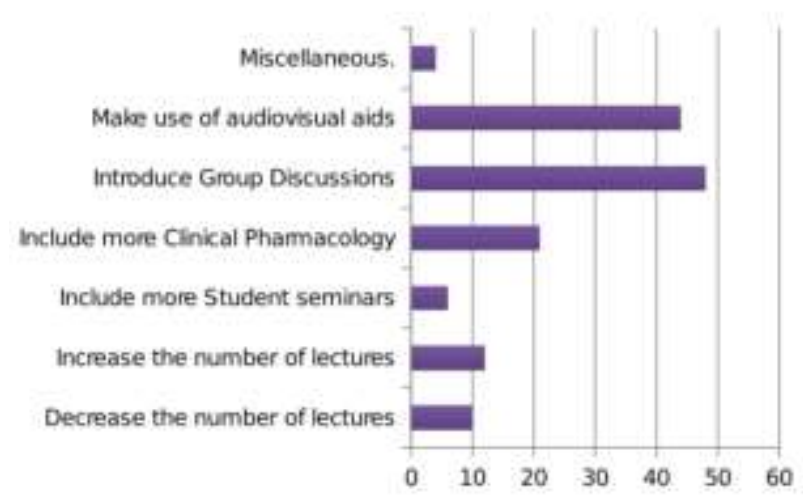

Figure 2: Students responses on reforms in pharmacology lectures $(\%)$.

Among the various topics in pharmacology, central nervous system (60\%), chemotherapy $(52 \%)$ and cardiovascular pharmacology $(42 \%)$ were considered the most interesting topics. Small number of students found gastrointestinal system (15\%), respiratory system (14\%), autacoids (14\%), endocrine pharmacology (12\%) and general pharmacology $(11 \%)$ as interesting. Only $8 \%$ of the students found all topics interesting. More than half of the students $(65 \%)$ were of the opinion that all topics in pharmacology will be useful in future. However, students considered chemotherapy $24 \%$, central nervous system $23 \%$, cardiovascular pharmacology $20 \%$, gastro intestinal system $15 \%$ and respiratory system $14 \%$ would be useful 
in future. Smaller proportions of students considered autacoids $9 \%$, general pharmacology and endocrines $5 \%$ each useful in future.

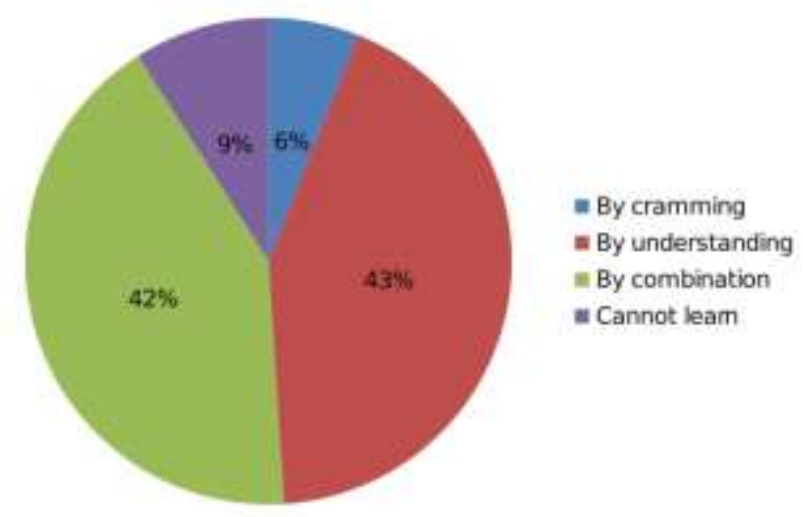

Figure 3: Students pattern of learning pharmacology lectures $(\%)$.

Of the teaching methodologies, more than half of the students $(62 \%)$ found interactive lectures most helpful in learning, whilst $39 \%$ and $20 \%$ of the students rated audio-visual aided lectures and demonstrations as a useful tool for learning respectively. Only $9 \%$ of students said that didactic lectures were useful for learning (Figure $1)$.

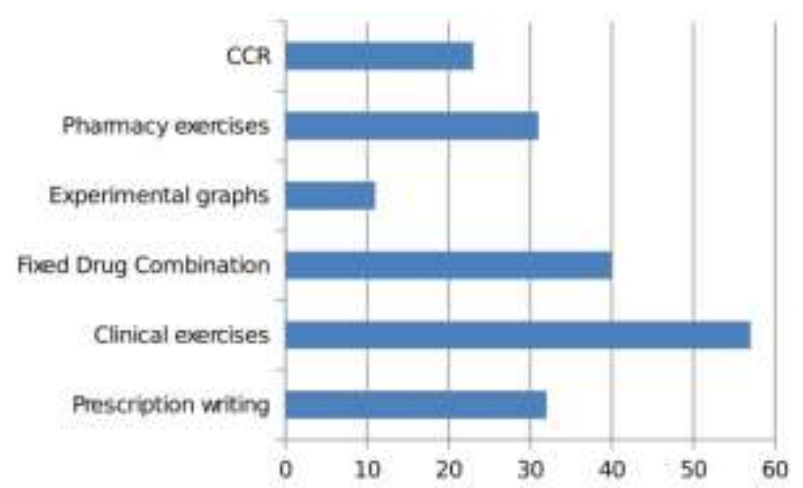

\section{Figure 4: Students preferences for pharmacology} practical classes $(\%)$.

Students rated the teaching sessions as some interestingsome boring $45 \%$, most interesting- some boring $42 \%$, always interesting 7\%, most boring- few interesting 5\% and always boring $1 \%$. In terms of reforms, $48 \%$ of the students suggested to introduce small group discussion hours, $44 \%$ suggested to make more use of audio-visual aids, $21 \%$ of the students wanted more clinical pharmacology , $12 \%$ wanted an increase in the lectures and $10 \%$ suggested decreasing the lectures and only $6 \%$ suggested to include more seminars (Figure 2).

Discussions at the end of class (55\%), encouraging students to ask questions during lectures (38\%) and discussing with individual student $21 \%$ were the main ways in which one could enhance active student participation in the class. Up to $38 \%$ of the students responded that their pattern of studying pharmacology is regular because of test/viva/tutorials, However, students also said that they study pharmacology regularly to gain more knowledge $(29 \%)$ and because of their interest in it (29\%). There were also $22 \%$ of the students who studied only for final examination.

For learning and preparing for examinations, $56 \%$ of the students used standard text books, $40 \%$ used handy books while $31 \%$ of the students prepared their own notes.

$26 \%$ of the students admitted to relying only on teachers notes. In preparing for examination combination of written exam and viva was helpful for $59 \%$ of the students, written class tests for $37 \%$ of students, tutorials for $16 \%$ of students, viva for $15 \%$ of students and midterm examination for $4 \%$ of students. In learning pharmacology $43 \%$ of students learnt by understanding the subject, $42 \%$ by combination of understanding and cramming and other $6 \%$ by only cramming. Only $9 \%$ of the students felt they cannot learn pharmacology (Figure 3).

Regarding practical classes in pharmacology, 57\% students found clinical exercises as interesting followed by comments on fixed dose combination $40 \%$, prescription writing 32\%, pharmacy exercises 31\%, CCR $23 \%$ and experimental graphs $11 \%$ (Figure 4 ).

For the need of pharmacology even after second year, $58 \%$ of the students said only recent advances while $38 \%$ of students opted for orientation course and smaller number of students (4\%) felt they had enough of pharmacology.

\section{DISCUSSION}

Pharmacology forms the backbone of rational therapeutics, being both a basic and applied science. The primary objective of teaching pharmacology is to enable undergraduate medical students to take rational therapeutic decisions in clinical practice. ${ }^{9}$

Pharmacology is also one of the most important and ever changing subjects in the medical curriculum. Students' perceptions and attitude regarding the different teachinglearning and evaluation methods are important for further development and restructuring of medical education in future. Students' feedback is also important for a medical teacher as it offers room towards his excellence.

In the present study, many interesting things came into picture and students suggested many ways that could be incorporated in conventional pharmacology teaching so as to make the subject more interesting and understandable. 
Majority of students knew about pharmacology before being introduced to them in second year. Pazzani showed that prior knowledge can influence the rate of concept learning. ${ }^{10}$ Pharmacology was a favourite subject to majority of students $62 \%$. In a study conducted by Sawhney V et al has revealed similar opinion from the students. $^{7}$

Students' favourite topics in pharmacology were central nervous system, chemotherapy and cardiovascular system as very useful for the future while least interesting were general pharmacology, endocrines, git, respiratory and autacoids. It seems that there is a need to improve methods of delivering these least interesting topics in a way that can raise interest and understanding amongst students. It is important to emphasize that all the topics are complementary to each other, and for better understanding of the subject, learning all topics is necessary. In our current study interactive lectures and audio-visual aided lectures were most helpful to the students compared to didactic lectures in learning pharmacology.

Students also suggested introducing smaller group discussions and including more clinical pharmacology oriented lectures. This shows that the students are now more interested in therapeutic and clinical pharmacology guidance. Therefore, incorporation of more case-based discussions into the small group sessions seems to enhance interest of students and is likely to be helpful in learning application of basic pharmacological concepts into clinical practice. A study conducted by Manjunath SM et al showed about $82 \%$ students in their study wanted group discussions to be introduced as a part of regular teaching. ${ }^{11}$ Students' seminars were rated lowest among teaching methods which is in consistent with studies done by other authors. ${ }^{12,13}$ As most of the students found seminars boring and useless, it is necessary to evaluate the ways in which seminars are conducted and make necessary changes

Active participation of the students in the class can be increased by holding discussion at the end of class and also encouraging students to ask question as revealed in our study.

Regular tests at the end of teaching module were the reason for studying pharmacology although some studied pharmacology to gain more knowledge and because of interest in it. Majority of the students used standard text books while few also used handy books for preparing for the examination. Many students prepared their own notes while few students relied on teachers notes. In a study conducted by Ghosh A et al Majority students (94.3\%) opined that distribution of hand-out giving outline of day's class should be a very good option. ${ }^{14}$

Respondents revealed that combination of written test and viva helped them in preparing for final examination. In practical pharmacology students found clinical exercises, fixed dose combination study and prescription writing as most interesting. This shows that students found more interest in those practical parts which are clinically oriented and needed in their future life. Students want to study recent advances in pharmacology even after the end of second year as it will help them in writing rational prescription.

Additional suggestions given were to conduct regular test on each topic, to provide hints, pneumonic and flow charts, entrance oriented questions at the end of each topic and to conduct quiz regularly.

\section{CONCLUSION}

It is important to know the students opinion on teaching of pharmacology and their learning methods so as to modify accordingly the undergraduate teaching program.

Formulating new educational strategies to meet the educational objectives of making pharmacology more interesting and practicable is the hours' need. We need to identify priority areas for feedback oriented improvement in the pharmacology. The results of our study can serve as positive feedback to make the teaching programme more interesting.

As teaching and learning is self-evolving process, a welldesigned and systematic prospective research needs to be carried out very often so that students get updated every year ensuring outcome of a quality efficient healthcare professional.

\section{ACKNOWLEDGEMENTS}

The authors would like to thank the fifth term and sixth term medical students of Shridevi Institute of Medical Sciences and Research Hospital, Tumkur for giving their honest feedback and participating in the study.

\section{Funding: No funding sources \\ Conflict of interest: None declared \\ Ethical approval: Not required}

\section{REFERENCES}

1. Rangachari PK. Basic sciences in an integrated medical curriculum: The case of pharmacology. Adv Health Sci Educ. 1997;2(2):163-71.

2. Garg PV, Rataboli K. Students' opinion on the prevailing teaching methods in pharmacology and changes recommended. Indian $\mathrm{J}$ Pharmacol. 2004;36(3):155-8.

3. Dawane JS, Pandit VA, Dhande PP. A Comparative study of Different Teaching Methodologies used for developing understanding of Cardiac Pharmacology in Undergraduate Medical Students. IOSR-J Research Method Education. 2014;4(3):34-8.

4. Amberkar M, Mohan L, Kumari M, Bairy KL. A Survey on Methods Of Undergraduate Pharmacology 
Teaching. Asian J Pharmaceutical Research Health Care. 2011:3(2):43-9.

5. Hariharan TS. Need for changes in the practical pharmacology curriculum of medical undergraduates. Indian J Pharmacol. 2004;36(3):181.

6. Gitanjali B, Shashindran $\mathrm{CH}$. Curriculum in clinical pharmacology for medical undergraduates of India. Indian J Pharmacol. 2006;38(S2):108-14.

7. Sawhney V, Bhat MY, Farhat S. A questionnaire based study of pharmacology Curriculum in undergraduate students. Int $\mathbf{J}$ Res Pharmacol Pharmacother. 2014; 3(4):382-6.

8. Dinesh DK, Bala S, Kathuria P. Students evaluation of teaching and assessment methods in pharmacology. Indian J Pharmacol. 2010;42(2):8789.

9. Vasundara K, Kanchan P, Pundarikaksha HP, Girish $\mathrm{K}$, Prassana S, Jyothi $\mathrm{R}$ Indian $\mathrm{J}$ Pharmacol. 2010;42(6):420
10. Pazzani MJ. Influence of prior knowledge on concept acquisition: experimental and computational results. J Exp Psychol Learn. 1991;7(3):416-32.

11. Manjunath SM, Nagesh Raju G, Srinivas TR, Someswara GM. A study on the evaluation of medical students' perception and feedback of teaching-learning of pharmacology in a medical college. International Archives of Integrated Medicine. 2015;2(9):102-10.

12. Sekhri K. Teaching methodologies in pharmacology: a survey of students' perceptions and experiences. J Educ Ethics Dent. 2012;2(1):40-4.

13. Chavda N, Yadav P, Karan J, Kantharia ND. Second MBBS medical student's feedback on teaching methodology and evaluation methods in Pharmacology. Natl J Physiol Pharm Pharmacol. 2011;1(1):23-31.

14. Ghosh A, Mandal K, Biswas S, Dalui SK, Haldar M, Biswas S. Evaluation of pharmacology teachinglearning methods in a government medical college. Int J Basic Clin Pharmacol. 2016;5:126-30.

Cite this article as: Prasad SR, Kudthni RH, Santhosh R. A questionnaire based study of students' opinion on the teaching and learning methods in pharmacology in a medical school of India. Int $\mathbf{J}$ Basic Clin Pharmacol 2016;5:2589-93. 